\title{
A Multilevel Examination of Peer Victimization and Bullying Preventions in Schools
}

\author{
Seokjin Jeong' and Byung Hyun Lee ${ }^{2}$ \\ ${ }^{1}$ Department of Criminology and Criminal Justice, University of Texas at Arlington, P.O. Box 19595, Arlington, TX 76019, USA \\ ${ }^{2}$ Michigan State University, East Lansing, MI, USA \\ Correspondence should be addressed to Seokjin Jeong; sjjeong@uta.edu
}

Received 4 March 2013; Revised 20 May 2013; Accepted 28 May 2013

Academic Editor: Christopher Schreck

Copyright (C) 2013 S. Jeong and B. H. Lee. This is an open access article distributed under the Creative Commons Attribution License, which permits unrestricted use, distribution, and reproduction in any medium, provided the original work is properly cited.

The goal of this study is twofold: (i) to develop an explanatory model to examine the relationship between school environment/climate and peer victimization and (ii) to determine whether previous models of preventive strategies in a single school or district could be expanded to the nationally representative sample of adolescents across multiple schools. The analyses in the current study are based on data from the Health Behavior in School-Aged Children (HBSC) 2005-2006 US study, and the sample consists of 7,001 students from 195 different schools. The findings reveal that students attending schools in which bullying prevention programs are implemented are more likely to have experienced peer victimization, compared to those attending schools without bullying prevention. Study limitations and implications for future research are discussed.

\section{Introduction}

Although many studies suggest that there is a decline in various types of peer victimization among school children [1, 2], bullying remains a serious problem in schools today [3-5]. Approximately 1.5 million school-aged adolescents (i.e., ages 12 to 18 ) report that they have been victimized by violence while at school [6]. Furthermore, 75 percent of public school principals in the United States indicate that their schools reported one or more violent incidents to the police, and 25 percent of public schools reported school bullying on a daily or weekly basis [6].

A growing body of research has supported the premise that experiencing school violence has devastating effects on youth [7-13]. For example, victims have experienced a significantly increased risk of internalizing and somatic symptoms, such as anxiety, depression, confusion, lowered self-esteem, and suicidal ideation $[7,10,11]$. Further, they are more likely to perceive a lack of support from peers and parents and tend to be isolated from social interaction with others [10]. In light of this reality, a variety of bullying prevention and intervention programs have been implemented and examined for their effectiveness [14-16]. Although these studies have examined varying levels of strategies, targets, and participants, the majority of them have demonstrated that comprehensive and whole-school efforts yield promising results for reducing bullying within school grounds.

The conditions of school environment, prevention/intervention programs, and situational factors complement or interact with individual-level characteristics to influence peer victimization $[17,18]$. Despite a range of ecological and contextual factors that are accountable for bullying involvement among adolescents (e.g., individual empathy, peer influence, family environment, teacher support), it still remains important to understand victim characteristics that are predictive of peer victimization. Previous studies of peer victimization, mostly based on a single dimension (i.e., individual-level or school-level predictor), have been limited in assessing the impact of bullying prevention because they ignore possible contributions of other ecological contexts in the surrounding environment. Relative to our concern about peer victimization and the need for promoting a safe school environment, only a small number of studies have examined the different ecological contexts of victimization (e.g., individual, peer, family, school) simultaneously. Thus, 
the main purpose of the current study is to examine the impact of multiple levels of ecological influence on peer victimization. Few researchers have examined individualand school-level predictors' influence on different forms of peer victimization. To date, the current study examines whether these predictors (i.e., demographic characteristics, parental or peer support, school climate, and implementation of prevention programs) show a significant effect on multiple forms of peer victimization (i.e., physical, emotional, or both physical and emotional).

\section{Prior Research on Peer Victimization}

2.1. School Bullying and Peer Victimization. Bullying can be difficult to conceptualize given the multifaceted nature of the violence involved. There is no simple explanation for which factors contribute to bullying $[12,19]$. A number of studies have relied on Olweus' (1993) [11] conceptual definition, in which bullying occurs whenever a student "is exposed repeatedly, over time, to negative actions on the part of one or more other students" [11, page 9]. Using this definition, bullying may be further characterized as the presence of (i) a power imbalance; (ii) intense intimidation; and (iii) a harmful effect on the victim $[11,19]$. Thus, school bullying may be defined as physical and/or emotional harm inflicted by other students within the geographical boundaries of a school ground [11]. The forms of school bullying range from teasing, taunting, or calling names to hitting, kicking, or taking/destroying others' belongings [11]. Studies of school bullying suggest that a significant number of students have been victims of school bullying [11, 20-22]. Approximately 8 percent to 41 percent of students reported being teased in a mean way or being hit, kicked, and/or pushed.

Bullying has detrimental effects on victims' well-being. First, the association between school bullying and victims' physical/psychological well-being and academic maladjustment is well documented [23-29]. For example, victims of school bullying are more likely to suffer psychological maladjustment, including sadness, depression, loneliness, and low self-esteem $[23,24,26,29]$. In addition, a significant association is found between peer victimization and extreme emotional responses such as suicidal ideation and suicide attempts $[25,29]$. Lastly, victimization can lead to interpersonal and academic difficulties at school. Bullied victims are more likely to experience relational problems with their peers, to be rejected by their peers, to feel aversion toward school, and to receive lower academic grades [23, 27].

2.2. Individual-Level Risk and Protective Factors. Among a number of risk and protective factors, a myriad of studies found that individual-level characteristics (i.e., age and race) are important sources of influence associated with peer victimization [24, 30-35]. With respect to race, minority youth are more frequently victimized by peers at school than are members of dominant racial groups $[24,32]$. Research also supports the notion that risk of peer victimization decreases with age [30, 32, 35]. Specifically, high-school students are less vulnerable to bullying victimization compared to elementary- and middle-school students. Further, the study by Graham et al. (2003) [24] examined the effect of gender and found that girls are more likely than boys to be bullied at school and to identify themselves as victims. However, types of victimization differ between boys and girls. While boys are more susceptible to physical victimization, girls are more susceptible to emotional or verbal victimization (e.g., rumor-spreading or gossiping) [36]. Finally, considerable research suggests that family and peer group contexts can be risk or protective factors in bullying victimization; both family and peer group contexts are significantly associated with students' experience of peer victimization [26, 37]. For example, students who are strongly rejected by their peers are seen as easy targets of school bullying [37]. The results from several prior studies also indicate that students who lack parental supervision and support tend to be more victimized than those who do not [26].

2.3. School-Level Risk and Protective Factors. In addition to individual-level characteristics, there is a growing body of literature suggesting that school-level characteristics (i.e., school security, school climate, and preventive education/intervention) are influential in predicting the likelihood of peer victimization $[17,18,38]$. Assuming that schoolrelated victimization is similar to other types of criminal victimization, the predictors of criminal victimization would be associated with, or explanative of, school-related victimization. Miethe and Meier (1994) [39] stressed that security and physical guardianship (i.e., locks, gates, alarm systems, and adult presence) have significant effects on victimization. Although the conclusions of studies on school-level security and its impact on the extent of school bullying victimization have been mixed [40], a significant relationship has been found between school security and physical guardianship and bullying victimization at school $[17,18,41]$. These studies found that students are less likely to be bullied when schools increase staff supervision, metal detectors, security cameras, locked entrances, visitor sign-in, visible student badges, and routine/random locker checks. Furthermore, students attending schools whose teachers are aware of school policies on bullying victimization and whose school professionals handle victimization problems adequately tend to be victimized less frequently [18].

\subsection{Effects of Preventive Strategies on Peer Victimization.} These findings clearly show that school violence and peer victimization require changes in school culture and climate in order to improve the safety of adolescents at school. Accordingly, many scholars and policy makers are paying increased attention to various preventive strategies that have been employed by schools [42]. Do these prevention strategies reduce the probability of school violence and peer victimization? Since prevention strategies (i.e., reactive/proactive responses, comprehensive approaches, and curriculum interventions) and their study designs show varying degrees of effectiveness [43], a number of empirical studies have reported mixed findings on strategies for reducing school violence and peer victimization $[11,19,44]$. One of the most widely used preventive strategies involves the implementation of new curricula and whole-school multidisciplinary 
interventions that aim to increase awareness of school violence, social cognitive skills, conflict resolution, and policy development [44]. For instance, Teglasi and Rothman (2001) [45] reported on a study examining the impact of 15 weeks of training and preventive education by using a quasiexperimental design. The authors found that participants of a new curriculum for social problem-solving skills were less likely to engage in aggressive behaviors. However, other researchers found that there was no statistically significant difference between an intervention curriculum group and a control group in decreasing bullying and victimization [46, 47].

Aside from a new curriculum, the main goal of wholeschool multidisciplinary interventions program (i.e., the Olweus Bullying Prevention Program) is to generate an effective, comprehensive response to and consequences for school violence [44]. Olweus (1993) [11] found that a comprehensive approach is effective in decreasing bullying victimization and antisocial behavior through improving school climate. As part of a broader outcome evaluation of the comprehensive approach, researchers reported supportive outcomes including decreased discipline referrals and suspension rates $[48,49]$. In sum, these prior studies have been evaluating the effectiveness of interventions into bullying and victimization by using experimental or quasiexperimental designs. Although these studies used different designs, samples, and statistical techniques, they have been generally supportive of the idea that whole-school interventions or a comprehensive approach is more effective than curriculum-based interventions based on classroom modules.

Despite reviews of the comprehensive prevention approach that reported on the effectiveness of programs in addressing school bullying, only a small number of studies found that school bullying prevention programs have no effect or little effect on reducing school violence [50, 51]. Based on meta-analysis, Ferguson and colleagues (2007) [50] reported that school antibullying programs show little discernible effect on violence and victimization of children in school settings. Payne and colleagues (2003) [51] conducted a study of the effects of communal school organizations (i.e., supportive and collaborative relations among administrators, teachers, and students) on school victimization. Of the 254 public secondary schools studied, they found that communal school organizations had no significant effect on reducing student victimization.

As programs designed to support vulnerable adolescents have significantly increased [52], a number of school programs have been developed to address safe environments and students' well-being. Safe Passage program is a model for reducing school problems by bringing together school staff members, parents, the local health department, the local social service agency, local youth organizations, and students [53]. Recently, by identifying best practices, Oakland, California, provided services targeted to vulnerable adolescents, including a violence-prevention curriculum, case management, mental health services, and after-school programs [54]. Results from studies on this comprehensive approach suggest that Safe Passage programs can be effective in delivering justice while increasing school safety compared to other school-based intervention programs. Specifically, violence-related suspension and overall suspension have been substantially decreased [54]. Although many of our public schools already implemented Safe Passage programs [53], only a small number of studies have evaluated its success.

\section{Research Questions and Hypotheses}

Despite the previous findings, few studies have tested the efficacy of intervention strategies on peer victimization. Furthermore, no study has examined the roles that intervention strategies and school climate play on different types of bullying victimization, particularly for distinct physical and emotional types of victimization. The current study seeks to address several issues that remain unresolved. First, this study focuses on developing an explanatory model to understand the relationship between school environment/climate and peer victimization. Second, it is evident from the literature review that research on prevention strategies of bullying is not rigorous enough. Existing research has tested the effectiveness of preventive strategies based on students in a single school site or district. Thus, little is known about whether these models could be expanded to a nationally representative sample of adolescents across multiple schools. Consequently, the current study suggests several research questions relevant to peer victimization.

(i) Did students' individual-level backgrounds (i.e., race, sex, age, parental support, peer support, and school pressure) affect the one's risk of vulnerability to peer victimization?

(ii) Did being minority, being male, being younger, having quality of parental support, having quality of peer support, and feeling higher level of school pressure increase the one's risk of vulnerability to peer victimization?

(iii) Did students' school-level characteristics (i.e., school security climate, implementation of safe passage program, implementation of Gang Prevention, and implementation of bullying prevention) affect the one's risk of vulnerability to peer victimization?

\section{Methodology}

4.1. Sample and Procedure. The analyses in the current study are based on data from the Health Behavior in SchoolAged Children (HBSC) 2005-2006 U.S. study. Sponsored by the World Health Organization (WHO), the HBSC study has been conducted every four years since 1985 to examine school-based behaviors of adolescents from more than 40 different countries. Funded by the United States Department of Health and Human Services, the HBSC study collected data with a nationally representative sample of students in public, Catholic, and other private schools. The HBSC survey component asks respondents about health problems and schoolrelated issues (e.g., bullying) through early adolescence. In addition, a school administrators' survey has been conducted to obtain school-level information on violence prevention policies and security practices. In order to obtain a nationally representative sample, data were collected from students 
(from sixth to tenth grades) and school administrators in the 50 states and the District of Columbia. Given that the purpose of the study is to understand school climate and violence prevention strategies related to peer victimization at school, the analyses were restricted to students attending schools whose administrators have completed a school-level survey. Among the 8,030 students who completed the survey through a multistate sampling, 2,226 students from 32 schools were excluded due to missing information of school-level indicators. Therefore, a total of 7,001 students from 195 different schools were eligible for the current study.

4.2. Dependent Variable. For the purpose of the present study, prevalence of peer victimization is operationalized as a dichotomous variable, with "0" indicating the student was not victimized and "1" indicating the student was victimized by other students on school grounds (we created the victimization item by summing seven items (i.e., how often got called names/teased, left out of things, hit/kicked/pushed, others lied about me, for race/color, for religion, and made sexual jokes to me) and dichotomizing them). A review of prior research suggests that certain characteristics of the victims increase the risk of different types of victimization. In response to these differences, victimizations are grouped into three categories: all victimization, physical victimization, and emotional victimization (peer victimization was based on Olweus' (1993) criteria: physical victimization and emotional victimization. Physical victimization was measured with one item, "I was hit, kicked, pushed, shoved around, or locked indoors." To measure emotional victimization, the following six items were used: "I was called mean names, was made fun of, or teased in a hurtful way," "other students left me out of things on purpose, excluded me from their group of friends, or completely ignored me," "other students told lies or spread false rumors about me and tried to make others dislike me," "I was bullied with mean names and comments about my race or color," "I was bullied with mean names and comments about my religion," "other students made sexual jokes, comments, or gestures to me." Similar to all types of victimization, we created each type of victimization by summing items and dichotomizing them so that each measure has a dichotomous (yes/no) response).

4.3. Individual-Level Variables. Three demographic background variables, Race, Sex, and Age (11 to 17), are included in the study. Race was originally incorporated as an exhaustive list from which respondents could select all categories that applied. Given the results, it was collapsed into a new dichotomous variable with 0 indicating non-white and 1 indicating White. Sex is also a dichotomous variable with 0 indicating female and 1 indicating male. Additional measures of individual characteristics were parental support, peer support, and school pressure. the parental support construct is measured by a combined scale of six items: parent helps me as much as I need; lets me do things I like doing; is loving; understands my problems; likes me to make my own decisions; and makes me feel better when upset. Responses were coded 1 to 3 : almost never, sometimes, and almost always. Then they were collapsed into new continuous variables with a higher score indicating more warmth and support from parents (Alpha $=$ .803). Peer support is measured as follows: students in my class enjoy being together; are kind and helpful; and accept me as I am. Responses were coded on a five-point Likert scale from 1 (strongly disagree) to 5 (strongly agree), then collapsed into new continuous variables with a higher score indicating more warmth and support from peers (Alpha $=.704)$. School pressure is included to assess the role of negative emotions on peer victimization. This item has four categories from 1 (not at all) to 4 (a lot).

4.4. School-Level Variables. Several prior studies [18, 38, 55] suggest that school characteristics and climate have significant effects on victimization. In response, the current study examines two different domains of school characteristics to reflect school climate and preventive strategies based on a survey of administrators. Four predictors related to peer victimization are used as measures of school-level characteristics: security climate, safe passage program, gang prevention program, and bullying prevention program. Six items are used to construct the variable of security climate, which asks questions about whether the school requires visitor check-in; maintains a closed campus; has staff/adults monitor the halls; conducts routine bag/locker checks; uses metal detectors; and has uniformed police. These items are measured by a dichotomous response, with 0 : no and 1 : yes, and collapsed into a single construct. The high value means a higher level of security climate on school grounds. Three preventive measures, safe passage, gang prevention, and bullying intervention, are used to reflect whether a school has or participates in preventive programs. Each item is a dichotomous variable, with 0 : no and 1: yes.

\section{Analytic Strategy}

To examine the empirical relationships among the variables described in the research question, the current study attempts to conduct multilevel modeling linking school-level contexts. Multilevel modeling (i.e., hierarchical linear modeling) is a powerful method of analysis for treating students as individual-level units and schools as school-level units [56]. This technique is appropriate for at least two reasons. First, it addresses the design effects that are inherent in the HBSC dataset, which utilizes a three-stage stratified design, with census divisions and grades as strata and school districts as primary sampling units [57]. Second, in order to address the research questions, we need to attend to the validity and model misfit due to hierarchically structured data. This technique allows researchers to resolve these problems while simultaneously investigating both within- and betweengroup variances [56]. Therefore, the multilevel modeling presented the current study's focus on school-level predictors of secure school climate and school-level prevention strategies, as well as the individual-level predictors. The two-level model consists of two submodels, one for each level (i.e., Level1 , the individual-level model and Level-2, the school-level model). While the Level-1 model represents the relationships among the individual-level predictors, the Level-2 model captures the influence of school-level covariates' effects. 
TABLE 1: Descriptive statistics of all variables $(N=7001)$.

\begin{tabular}{|c|c|c|c|c|}
\hline & $N(\%)$ & Mean (St. deviation) & Minimum & Maximum \\
\hline \multicolumn{5}{|l|}{ Individual-level variables } \\
\hline Race: white (\%) & $3268(46.7)$ & & 0 & 1 \\
\hline Sex: male (\%) & $3348(47.8)$ & & 0 & 1 \\
\hline Age (mean) & & $13.67(1.47)$ & 11 & 17 \\
\hline Parental support (mean) & & $14.56(2.76)$ & 6 & 18 \\
\hline Peer support (mean) & & $10.49(2.55)$ & 3 & 15 \\
\hline School pressure: (mean) & & $2.56(1.01)$ & 1 & 4 \\
\hline \multicolumn{5}{|l|}{ School-level variables } \\
\hline Security climate (mean) & & $4.04(1.33)$ & 0 & 6 \\
\hline Safe Passage: yes (\%) & $1593(22.8)$ & & 0 & 1 \\
\hline Gang prevention: yes (\%) & $3115(44.5)$ & & 0 & 1 \\
\hline Bullying prevention: yes (\%) & $4581(65.4)$ & & 0 & 1 \\
\hline \multicolumn{5}{|l|}{ Peer victimization } \\
\hline All victimization & $3845(54.9)$ & & 0 & 1 \\
\hline Physical victimization & $962(13.7)$ & & 0 & 1 \\
\hline Emotional victimization & $3721(53.1)$ & & 0 & 1 \\
\hline
\end{tabular}

Due to the hierarchical nature of the current data (students nested within schools) and the nature of binary outcomes (victimized within school grounds), multilevel mixed-effects logistic regressions are conducted using STATA 12.0.

\section{Results}

6.1. Descriptive Statistics. Table 1 illustrates the descriptive statistics for the dependent and independent variables used in the current study. Of 7,001 students, approximately 55 percent reported experiencing some form of peer victimization during the school year. In particular, among those bullied students, slightly more than half $(53.1 \%)$ of the students had been emotionally bullied (i.e., being called names, victims of rumors, or ignored), and about 14 percent of the students had experienced physical bullying (i.e., being hit, kicked, pushed, shoved around, or locked indoors). Table 1 also shows that the sample population was 47 percent white and 48 percent male, whose mean age was 14.67 ( $\mathrm{sd}=1.47)$, and who received warmth and support from their parents (mean $=15.56$ and $s d=2.76)$ and peers ( mean $=10.49$ and $s d=2.55)$. However, students in the current study felt significant levels of stress regarding school work $($ mean $=2.56$ and $\mathrm{sd}=1.01)$.

School-level variables reported by a sample of 195 school administrators are also illustrated in Table 1. Of the six security measures listed under the security climate item, the mean number of security measures was 4.04 ( $\mathrm{sd}=$ 1.33). The majority of schools have around four security measures among six possible strategies, such as visitor checkin, a closed campus, staff/adult hall monitors, bag/locker checks, metal detectors, and uniformed police. In terms of preventive school programs, the majority of schools have bullying prevention programs (65.4\%). Approximately 45 percent of school administrators reported that their schools have implemented gang prevention programs, followed by Safe Passage programs (22.8\%).
6.2. Bivariate Analysis. As a preliminary measure, bivariate correlations among individual-level and school-level variables are computed (Table 2). As expected, the individuallevel characteristics (i.e., sex, age, parental support, and peer support) were negatively correlated with ever being victimized. In contrast, the level of stress about schoolwork was positively related to the experience of peer victimization. At the school level, although it was hypothesized that these security-related predictors would be related to victimization, there were no significant associations between security climates, Safe Passage program, gang prevention, and peer victimization. Unexpectedly, however, there was positive association between bullying-prevention programs and peer victimization.

6.3. Multilevel Models. Multilevel models are constructed to determine whether the prevalence of peer victimization, physical victimization, and emotional victimization varies according to school-level predictors (the basic unconditional model was first conducted to determine the proportion of the variance in outcome between the schools. An analysis of the intraclass correlations reveals that around 7 percent $($ ICC $=$ .065 ) of the variance in peer victimization (both physical and emotional victimization) is accounted for by differences in the characteristics of the schools. Although most of the variance in student-level characteristics (around 90\%) was attributed to within-school variance, the between-school variance was statistically significant). Table 3 presents the results of models that include the individual-level and schoollevel variables for all three types of victimization (Model 1) and for specific types of victimization (Models 2 and 3) from competing risks models (for interpretation, the estimated coefficients have been transformed into odds ratios). Level1 of Model 1 shows the general pattern of individual-level differences in odds ratios for victimization cases. Specifically, male students were .67 times less likely than female students 
TABLE 2: Correlations of individual-level and school-level covariates.

\begin{tabular}{|c|c|c|c|c|c|c|c|c|c|c|c|}
\hline & 1 & 2 & 3 & 4 & 5 & 6 & 7 & 8 & 9 & 10 & 11 \\
\hline \multicolumn{12}{|l|}{ Individual-level variables } \\
\hline (1) Race (1: white) & 1 & & & & & & & & & & \\
\hline (2) Sex (1: male) & .012 & 1 & & & & & & & & & \\
\hline (3) Age & .057 & .043 & 1 & & & & & & & & \\
\hline (4) Parental support & .139 & .032 & -.049 & 1 & & & & & & & \\
\hline (5) Peer support & .021 & .011 & .010 & .287 & 1 & & & & & & \\
\hline (6) School pressure & .042 & -.074 & .080 & -.138 & -.088 & 1 & & & & & \\
\hline \multicolumn{12}{|l|}{ School-level variables } \\
\hline (7) Security climate & -.181 & .006 & .059 & -.069 & -.049 & -.040 & 1 & & & & \\
\hline (8) Safe Passage (1: yes) & -.142 & -.013 & -.056 & -.042 & .001 & -.015 & .220 & 1 & & & \\
\hline (9) Gang prevention (1: yes) & -.151 & .001 & -.095 & -.012 & -.005 & -.028 & .236 & .357 & 1 & & \\
\hline (10) Bullying prevention (1: yes) & -.059 & .001 & -.259 & .027 & -.025 & -.026 & .158 & .239 & .544 & 1 & \\
\hline \multicolumn{12}{|l|}{ Peer victimization } \\
\hline (11) Victimization & .010 & -.103 & -.111 & -.139 & -.214 & .119 & -.010 & -.011 & -.014 & .046 & 1 \\
\hline
\end{tabular}

(1) Bolded coefficients denote $P<0.05$.

(2) As a preliminary measure, only overall victimizations were included in bivariate analysis.

TABLE 3: Multilevel mixed-effects logistic regression $(N=7001)$.

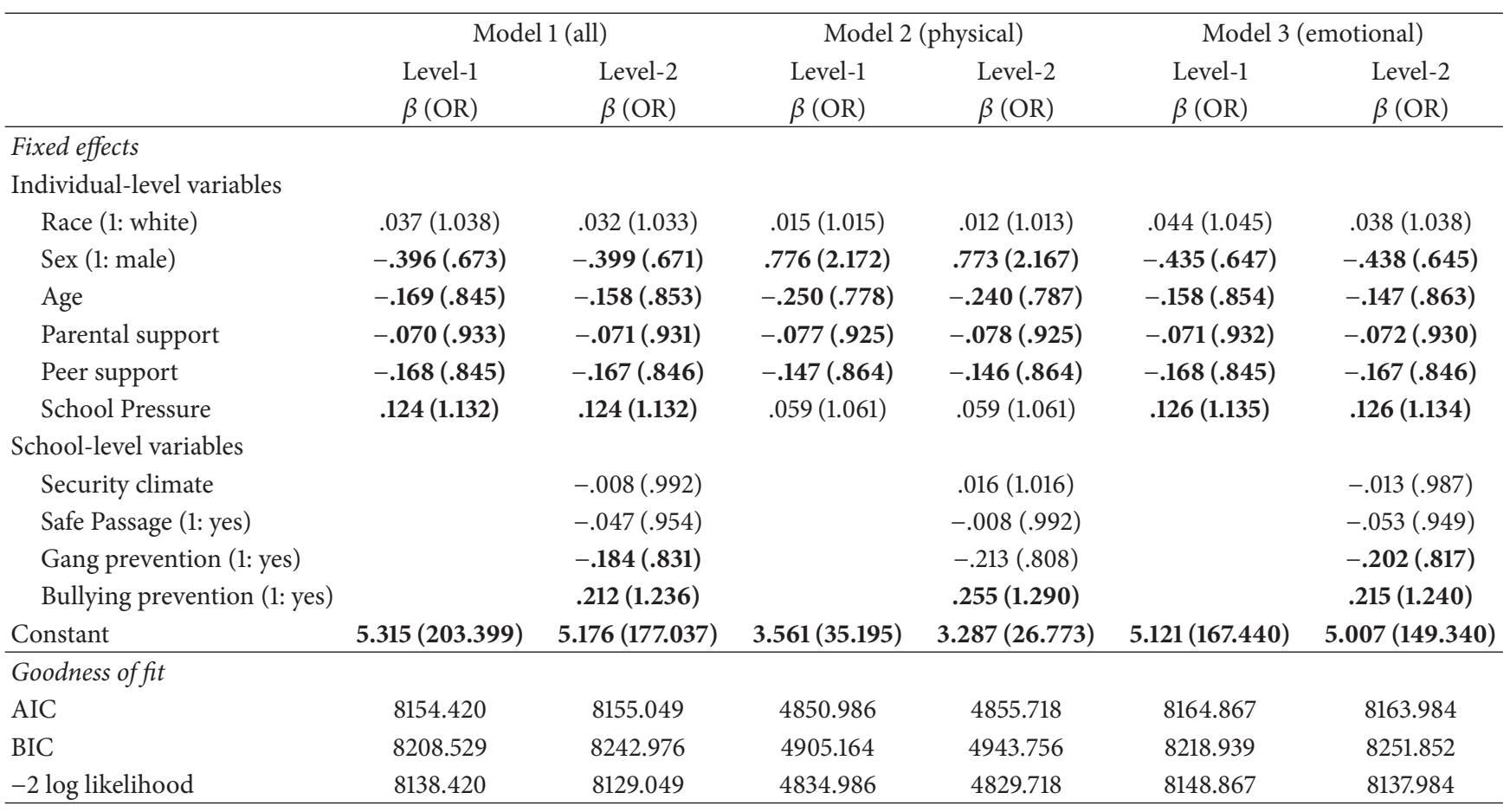

(1) Bolded coefficients denote $P<0.05$.

(2) Null model (equivalent to a one-way ANOVA with schools as a random effect) for each dependent variable that is not reported.

to report victimization. In addition, older students were 15 percent less likely than younger students to be victims of school bullying. Those with more warmth, parent support, and peer support were less likely to be victims of school bullying $(\mathrm{OR}=.933$ and $\mathrm{OR}=.845$, resp. $)$. In contrast, students with a higher level of stress about schoolwork were 1.13 times more likely to report victimization than those with a lower level of stress. After controlling for school-level variables, the results of individual-level effects were consistent with our predictions (see Model 1). As expected, the results show that gang prevention programs had significant effects on peer victimization. More specifically, students attending schools where gang prevention programs are provided were less likely to report victimization $(\mathrm{OR}=.831)$. For other schoollevel predictors such as security climate and Safe Passage programs, we proposed that students attending schools with Safe Passage programs or more secure climates were less likely to be victimized. This hypothesis was not supported. 
Interestingly, bullying prevention programs were negatively related to peer victimization. That is, students attending schools with bullying prevention programs were more likely to have experienced peer victimization $(\mathrm{OR}=1.236)$.

Model 2 in Table 3 shows the effects of individuallevel predictors on physical victimization. Similar to Model 1 (all types of victimization), the effects of age, parental support, and peer support were also significant and in the predicted directions, indicating decreased risk of being physically victimized. The effect of the level of stress due to schoolwork was not significant in Model 2. However, being male was a significant predictor of physical victimization with a different direction compared to Model 1. That is, male students were 2.17 times more likely than female students to become victims of physical bullying. With the addition of school-level variables into the model, individual-level predictors were consistent with the individual-level model in Model 2. Notably, it was not expected that providing bullying prevention programs would be found as a significant predictor of physical victimization $(\mathrm{OR}=1.290)$.

Model 3 presents results from a multilevel logistic regression for emotional victimization. In the Level-1 model with individual-level predictors, a number of predictors were significantly related to emotional victimization. Emotional victimization was negatively associated with being male, being older, and having more warmth, parental support, and peer support. With the addition of the school-level variables into the Level-2 model (see Level-2 model in Model 3), security climate and Safe Passage programs at the school level were not found to be significantly associated with emotional victimization. Contrary to our hypotheses, students attending schools with bullying prevention programs were more likely to have experienced peer victimization $(\mathrm{OR}=1.240)$.

\section{Conclusion and Discussion}

The current study investigated individual- and school-level differences in bullying victimization among peers in school. With respect to individual-level factors, both age and gender were important predictors of different types of peer victimization. Age had a positive effect on all three types of peer victimization. This is consistent with the literature that peer victimization appears to decrease with age; older students were less likely to be victims of bullying than younger students $[30,35]$. Gender also had an effect on all three types of peer victimization. Boys were more likely than girls to be victims of physical bullying, but girls were more likely to be victims of emotional bullying. These findings are consistent with prior studies' conclusions that the type of victimization varies according to gender $[24,36]$.

However, inconsistent with prior findings, race did not have an impact on peer victimization. The current study found no statistically significant difference across race. This is contrary to our prediction that minority adolescents are more likely to experience higher rates of bullying victimization, compared to Caucasian adolescents [31]. Given that more than half of the sample was in the non-white category, victimization directed toward minority students may not be apparent. Although existing bullying prevention programs address the factors that may increase the risk of bullying across race, they often do not take into account sociorelational contexts as important sources of adolescents' learning process that influence bullying behaviors. Spriggs et al. (2007) [33] argued that the effects of family, peer, and school relationships on bullying involvement differ according to race. Being able to recognize and address these differences across racial groups will help to develop a better understanding of the dynamics of bullying victimization and to produce effective bullying prevention and intervention tailored to the populations being served.

Both parental and peer support represent significant predictors of peer victimization. The finding that parental support was predictive of both types of peer victimization suggests that parent-child interaction has a considerable effect on the likelihood of peer victimization. While parental support may play a protective role against peer victimization, lack of involvement and support from parents is likely to increase the risk of bullying victimization [26]. Peer support also was predictive of peer victimization, both physical and emotional. Negative peer relationships and lack of peer support may pose as risk factors conducive to bullying in schools $[33,37]$. On the other hand, having peer support reduces the likelihood of peer victimization [58]. Finally, school pressure had an effect on emotional victimization. Those facing a high level of school pressure are more likely to experience negative emotions and to be involved in bullying, as an aggressor and a victim, compared to those with a low level of school pressure [59].

Our prediction that students in schools with more security measures would be less likely to be victimized was not supported by the study findings. It must be noted that the security measure item contains elements that focus mainly on security on school grounds and the physical safety of students. In order to improve school safety, schools have implemented security measures such as video cameras, bag/locker searches, metal detectors, and other surveillance programs $[42,60]$. Studies have found that peer bullying victimization is less likely to occur if schools increase the level of security and safety for students through adult monitoring [41, 61]. For instance, uniformed officers can be useful for deterring bullying behaviors, but the utility of the other components of security climate (e.g., visitor check-in, a closed campus) in preventing bullying is not well documented. Further, security measures are just one element of the school climate. Other elements, such as teachers' awareness of antibullying policies and strategies, can intervene to reduce peer victimization. Schools in which teachers are aware of school policies on bullying victimization tend to have fewer incidents of bullying victimization [18]. Peer and teacher relations as well as the degree of aggressiveness in a school climate are also associated with bullying offending and victimization [41]. By improving several aspects of the school climate, a comprehensive approach can be effective in reducing bullying victimization and antisocial behavior [11].

For the school-level predictors, gang and bullying prevention programs were found to be significant predictors of peer victimization. However, gang prevention had only a partial effect. Although gang prevention had an impact on emotional 
victimization, it did not indicate any effect on physical victimization. One possible explanation is that strategies for schoolbased gang prevention (e.g., zero tolerance policies) may have proven to be ineffective in reducing physical victimization. Furthermore, whether or not school personnel are committed to implementing the program can be another important facet to consider. For example, the attitude of supervising teachers and staff members in supporting the prevention curriculum and communicating with the students can affect the overall effectiveness of these prevention programs $[62,63]$. Teacher monitoring is considered to be an important protective factor against peer victimization because the likelihood of students reporting bullying incidents depends on teachers responsiveness [64].

Surprisingly, bullying prevention had a negative effect on peer victimization. Contrary to our hypothesis, students attending schools with bullying prevention programs were more likely to have experienced peer victimization, compared to those attending schools without bullying prevention programs. It is possible that bullies have learned a variety of antibullying techniques but chose not to practice what they have learned from the program. Sometimes, bullies maintain their dominant social status among peers in school. As a result, the preventive strategies may become ineffective.

The other preventive measure, the Safe Passage program, had no effect on the likelihood of peer victimization. As a program designed to support at-risk adolescents, the program's goal is to create a safe school environment by reducing various school problems [52]. However, we did not find any significant impact on peer victimization. Without knowing specific details of the program, it is difficult to assess the effectiveness of the Safe Passage program.

Although prior research suggests that school-level characteristics (such as school security or a preventive curriculum) may be influential in predicting the likelihood of peer victimization $[17,18,38]$, it should be noted that the effectiveness of bullying prevention has yet to be proven. A meta-analysis indicates that bullying prevention programs specifically targeting at-risk youth were slightly effective in reducing bullying or violent behaviors on campus, but generally had a minimal effect on bullying and victimization [50]. Future direction needs to focus not merely on implementation of bullying prevention but rather on its effectiveness. Using a comprehensive approach (both an individual-level and a school-level approach), prevention efforts must move beyond individual risk factors and focus on systemic change within the schools. Furthermore, given that bullying is a relationship problem, researchers need to better identify the bully-victim dynamics in order to develop prevention strategies accordingly.

\section{Limitations and Future Directions for Research}

The current study used multilevel modeling to address the need to simultaneously examine the effect of individualand school-level variables on peer victimization. This type of modeling allows one to determine the amount of variance in the dependent variable that is explained by the individual-level factors (e.g., age, parental support) as well as school-level factors (e.g., security climate, preventive measure).

A number of limitations in the current study must be addressed in future research. First, the cross-sectional nature of the study limits one from making a causal inference about the relationship between individual- and school-level factors and likelihood of peer victimization. Future studies need to utilize a longitudinal design in investigating the temporal ordering between the preventive measures and peer victimization in schools. Second, no specific information concerning the prevention measures, specifically bullying prevention and gang prevention programs, is provided. The HBSC data contain limited information about these bullying prevention programs. Future research needs to examine the specific components of the prevention programs. Because the preventive measures in the current study were dichotomous, it is limited in understanding the impact of preventive strategies on peer victimization. Lastly, while school bullying among adolescents can be categorized into different types (e.g., physical, verbal, relational, cyber) [65], the current study is limited to physical and emotional victimization. As a result, we are not able to examine the distinct nature of the different forms of bullying and their relations with other factors.

\section{References}

[1] D. Finkelhor, H. Turner, R. Ormrod, and S. L. Hamby, “Trends in childhood violence and abuse exposure: evidence from 2 national surveys," Archives of Pediatrics and Adolescent Medicine, vol. 164, no. 3, pp. 238-242, 2010.

[2] M. Molcho, W. Craig, P. Due et al., "Cross-national time trends in bullying behaviour 1994-2006: findings from Europe and North America," International Journal of Public Health, vol. 54, no. 2, pp. S225-S234, 2009.

[3] F. DeVoe and K. Chandler, Student Reports of Bullying: Results from the 2001 School Crime Supplement to the National Crime Victimization Survey, U.S. Department of Education, National Center for Education Statistics, Washington, DC, USA, 2005.

[4] D. C. Gottfredson, Schools and Delinquency, Cambridge University Press, New York, NY, USA, 2001.

[5] B. Moon, H.-W. Hwang, and J. D. McCluskey, "Causes of school bullying: empirical test of a general theory of crime, differential association theory, and general strain theory," Crime and Delinquency, vol. 57, no. 6, pp. 849-877, 2011.

[6] R. Dinkes, E. F. Cataldi, G. Kena, and K. Baum, Indicators of School Crime and Safety, U.S. Department of Education, Washington, DC, USA, 2009.

[7] J. A. Dake, J. H. Price, and S. K. Telljohann, "The nature and extent of bullying at school," Journal of School Health, vol. 73, pp. 173-180, 2003.

[8] S. Greenbaum, B. Turner, and R. D. Stephens, Set Straight on Bullies, Pepperdine University Press, Los Angeles, Calif, USA, 1988.

[9] J. Isaacs, E. Hodges, and C. Salmivalli, "Long-term consequences of victimization: a follow-up from adolescence to young adulthood," European Journal of Developmental Science, vol. 2, pp. 387-397, 2008.

[10] R. Kaltiala-Heino, R. M. Rimpelä M, P. Rantanen, and A. Rimpelä, "Bullying at school—an indicator of adolescents at risk 
for mental disorders," Journal of Adolescence, vol. 23, no. 6, pp. 661-674, 2000.

[11] D. Olweus, Bullying at School, Blackwell Publishers, Malden, Mass, USA, 1993.

[12] K. Rigby, New Perspectives on Bullying, Jessica Kingsley, London, UK, 2002.

[13] G. Salmon, A. James, E. L. Cassidy, and M. A. Javaloyes, "Bullying a review: presentations to an adolescent psychiatric service and within a school for emotionally and behaviourally disturbed children," Clinical Child Psychology and Psychiatry, vol. 5, no. 4, pp. 563-579, 2000.

[14] N. S. Bauer, P. Lozano, and F. P. Rivara, "The effectiveness of the Olweus Bullying Prevention Program in public middle schools: a controlled trial," Journal of Adolescent Health, vol. 40, no. 3, pp. 266-274, 2007.

[15] A. Hallford, C. Borntrager, and J. L. Davis, "Evaluation of a bullying prevention program," Journal of Research in Childhood Education, vol. 21, no. 1, pp. 91-101, 2006.

[16] K. S. Whitted and D. R. Dupper, "Best practices for preventing or reducing bullying in schools," Children and Schools, vol. 27, no. 3, pp. 167-174, 2005.

[17] D. L. Espelage and S. M. Swearer, Bullying in American Schools: A Social-Ecological Perspective on Prevention and Intervention, Erlbaum, Mahwah, NJ, USA, 2004.

[18] P. K. Smith and S. Shu, "What good schools can do about bullying: findings from a survey in English schools after a decade of research and action," Childhood, vol. 7, no. 2, pp. 193212, 2000.

[19] P. R. Smokowski and K. H. Kopasz, "Bullying in school: an overview of types, effects, family characteristics, and intervention strategies," Children and Schools, vol. 27, no. 2, pp. 101-109, 2005.

[20] P. Orpinas, S. Kelder, R. Frankowski, N. Murray, Q. Zhang, and A. McAlister, "Outcome evaluation of a multi-component violence-prevention program for middle schools: the Students for Peace project," Health Education Research, vol. 15, no. 1, pp. 45-58, 2000.

[21] D. L. Silvernail, A. M. Thompson, Z. Yang, and H. J. Kopp, “A survey of bullying behavior among Maine third graders," 2000, http://usm.maine.edu/cepare/pdf/ts/br.pdf.

[22] P. K. Smith, L. Talamelli, H. Cowie, P. Naylor, and P. Chauhan, "Profiles of non-victims, escaped victims, continuing victims and new victims of school bullying," British Journal of Educational Psychology, vol. 74, no. 4, pp. 565-581, 2004.

[23] S. K. Egan and D. G. Perry, "Does low self-regard invite victimization?” Developmental Psychology, vol. 34, no. 2, pp. 299-309, 1998.

[24] S. Graham, A. Bellmore, and J. Juvonen, "Peer victimization in Middle school: when self- and peer views diverge," Journal of Applied School Psychology, vol. 19, pp. 117-138, 2003.

[25] D. S. J. Hawker and M. J. Boulton, “Twenty years' research on peer victimization and psychosocial maladjustment: a metaanalytic review of cross-sectional studies," Journal of Child Psychology and Psychiatry and Allied Disciplines, vol. 41, no. 4, pp. 441-455, 2000.

[26] D. L. Haynie, T. Nansel, P. Eitel et al., "Bullies, victims, and bully/victims: distinct groups of at-risk youth," Journal of Early Adolescence, vol. 21, no. 1, pp. 29-49, 2001.

[27] T. R. Nansel, M. Overpeck, R. S. Pilla, W. J. Ruan, B. SimonsMorton, and P. Scheidt, "Bullying behaviors among US youth: prevalence and association with psychosocial adjustment," Journal of the American Medical Association, vol. 285, no. 16, pp. 2094-2100, 2001.

[28] J. Paul and A. Cillessen, "Dynamics of peer victimization in early adolescence: results from a four-year longitudinal study," Journal of Applied School Psychology, vol. 19, pp. 25-43, 2003.

[29] W. Troop-Gordon and G. W. Ladd, "Trajectories of peer victimization and perceptions of the self and schoolmates: precursors to internalizing and externalizing problems," Child Development, vol. 76, no. 5, pp. 1072-1091, 2005.

[30] J. F. DeVoe, K. Peter, P. Kaufman et al., Indicators of School Crime and Safety, U.S. Department of Education, Washington, DC, USA, 2004.

[31] L. D. Hanish and N. G. Guerra, "The roles of ethnicity and school context in predicting children's victimization by peers," American Journal of Community Psychology, vol. 28, no. 2, pp. 201-223, 2000.

[32] D. Olweus, "Bully/victim problems among school children: basic facts and effects of a school based intervention program," in The Development and Treatment of Childhood Aggression, D. J. Pelpler and K. H. Rubin, Eds., Erlbaum, Hillsdale, NJ, USA, 1991.

[33] A. L. Spriggs, R. J. Iannotti, T. R. Nansel, and D. L. Haynie, "Adolescent bullying involvement and perceived family, peer and school relations: commonalities and differences across race/ethnicity," Journal of Adolescent Health, vol. 41, no. 3, pp. 283-293, 2007.

[34] M. S. Stockdale, S. Hangaduambo, D. Duys, K. Larson, and P. D. Sarvela, "Rural elementary students', parents', and teachers' perceptions of bullying," American Journal of Health Behavior, vol. 26, no. 4, pp. 266-277, 2002.

[35] I. Whitney and P. Smith, "A survey of the nature and extent of bullying in junior/middle and secondary schools," Educational Research, vol. 35, pp. 3-25, 1993.

[36] N. R. Crick and M. A. Bigbee, "Relational and overt forms of peer victimization: a multiinformant approach," Journal of Consulting and Clinical Psychology, vol. 66, no. 2, pp. 337-347, 1998.

[37] P. C. Rodkin and E. V. E. Hodges, "Bullies and victims in the peer ecology: four questions for psychologists and school professionals," School Psychology Review, vol. 32, no. 3, pp. 384400, 2003.

[38] A. Payne and D. Gottfredson, "Schools and bullying: school factors related to bullying and school based bullying interventions," in Bullying: Implications for the Classroom, C. Sanders and G. Phye, Eds., pp. 159-176, Elsevier Academic Press, San Francisco, Calif, USA, 2004.

[39] T. D. Miethe and R. F. Meier, Crime and Its Social Context: Toward an Integrated Theory of Offenders, Victims, and Situations, State University of New York Press, Albany, NY, USA, 1994.

[40] C. J. Schreck, J. M. Miller, and C. L. Gibson, "Trouble in the school yard: a study of the risk factors of victimization at school," Crime and Delinquency, vol. 49, no. 3, pp. 460-484, 2003.

[41] C. M. Wienke Totura, C. MacKinnon-Lewis, E. L. Gesten et al., "Bullying and victimization among boys and girls in middle school: the influence of perceived family and school contexts," Journal of Early Adolescence, vol. 29, no. 4, pp. 571-609, 2009.

[42] J. Juvonen, School Violence: Prevalence, Fears, and Prevention, Rand, Santa Monica, Calif, USA, 2001. 
[43] G. Sugai and R. Horner, "The evolution of discipline practices: school-wide positive behavior supports," Child and Family Behavior Therapy, vol. 24, no. 1-2, pp. 23-50, 2002.

[44] R. C. Vreeman and A. E. Carroll, "A systematic review of schoolbased interventions to prevent bullying," Archives of Pediatrics and Adolescent Medicine, vol. 161, no. 1, pp. 78-88, 2007.

[45] H. Teglasi and L. Rothman, "A classroom-based program to reduce aggressive behavior," Journal of School Psychology, vol. 39, no. 1, pp. 71-94, 2001.

[46] C. Kaiser-Ulrey, Bullying in Middle School: A Study of BEST: An Anti-Bullying Program for Seventh Grade Students, Florida State University Press, Tallahassee, Fla, USA, 2003.

[47] E. Sanchez, T. Robertson, C. Lewis, B. Rosenbluth, T. Bohman, and D. Casey, "Preventing bullying and sexual harassment in elementary schools: the expect respect model," in Bullying Behavior: Current Issues, Research, and Interventions, R. Geffner, M. Loring, and C. Young, Eds., pp. 157-180, Haworth Maltreatment and Trauma Press, New York, NY, USA, 2001.

[48] C. Metzler, A. Biglan, J. Rusby, and J. Sprague, "Evaluation of a comprehensive behavior management program to improve school-wide positive behavior support," Education and Treatment of Children, vol. 24, pp. 448-479, 2001.

[49] S. W. Twemlow, P. Fonagy, F. C. Sacco, M. L. Gies, R. Evans, and R. Ewbank, "Creating a peaceful school learning environment: a controlled study of an elementary school intervention to reduce violence," American Journal of Psychiatry, vol. 158, no. 5, pp. 808-810, 2001.

[50] C. J. Ferguson, C. S. Miguel, J. C. Kilburn Jr., and P. Sanchez, "The effectiveness of school-based anti-bullying programs: a meta-analytic review," Criminal Justice Review, vol. 32, no. 4, pp. 401-414, 2007.

[51] A. A. Payne, D. C. Gottfredson, and G. D. Gottfredson, "Schools as communities: the relationships among communal school organization, student bonding, and school disorder," Criminology, vol. 41, no. 3, pp. 749-777, 2003.

[52] M. J. Furlong, G. M. Morrison, and J. L. Greif, "Reaching an American consensus: reactions to the special issue on school bullying," School Psychology Review, vol. 32, no. 3, pp. 456-470, 2003.

[53] J. G. Dryfoos, Safe Passage: Making It through Adolescence in a Rrisky Society, Oxford University Press, New York, NY, USA, 1998.

[54] Safe Passages, After-School Landscape, Analysis, \& Recommendations for Sustainability, Safe Passages, Oakland, Calif, USA, 2005, http://www.safepassages.org/PDF/afterSchoolSustainability_Oakland.pdf.

[55] M. K. Holt and D. L. Espelage, "A cluster analytic investigation of victimization among high school students: are profiles differentially associated with psychological symptoms and school belonging?" Journal of Applied School Psychology, vol. 19, no. 2, pp. 81-98, 2003.

[56] S. W. Raudenbush and A. Bryk, Hierarchical Linear Models: Applications and Data Analysis Methods, Sage Publications, Newbury Park, Calif, USA, 2nd edition, 2002.

[57] R. J. Iannotti, Health Behavior in School-Aged Children (HBSC), 2005-2006. ICPSR28241-V1, Inter-University Consortium for Political and Social Research, Ann Arbor, Mich, USA, 2012.

[58] C. Salmivalli, "Bullying and the peer group: a review," Aggression and Violent Behavior, vol. 15, no. 2, pp. 112-120, 2010.

[59] J. G. Freeman, O. Samdal, D. A. Klinger et al., "The relationship of schools to emotional health and bullying," International Journal of Public Health, vol. 54, no. 2, pp. S251-S259, 2009.
[60] C. A. Garcia, "School safety technology in America: current use and perceived effectiveness," Criminal Justice Policy Review, vol. 14, pp. 30-54, 2003.

[61] S. Kasen, K. Berenson, P. Cohen, and J. G. Johnson, "The effects of school climate on changes in aggressive and other behaviors related to bullying," in Bullying in American Schools: A Social-Ecological Perspective on Prevention and Intervention, D. L. Espelage and S. M. Swearer, Eds., pp. 187-210, Erlbaum, Mahwah, NJ, USA, 2004.

[62] J. F. Donnermeyer and T. N. Wurschmidt, "Educators' perceptions of the D.A.R.E. program," Journal of Drug Education, vol. 27, no. 3, pp. 259-276, 1997.

[63] D. Peterson and F.-A. Esbensen, "The outlook is G.R.E.A.T.: what educators say about school-based prevention and the Gang Resistance Education and Training (G.R.E.A.T.) program," Evaluation Review, vol. 28, no. 3, pp. 218-245, 2004.

[64] B. Doll, S. Song, and E. Siemers, "Classroom ecologies that support or discourage bullying," in Bullying in American Schools: A Social-Ecological Perspective on Prevention and Intervention, D. L. Espelage and S. M. Swearer, Eds., pp. 161-183, Erlbaum, Mahwah, NJ, USA, 2004.

[65] J. Wang, R. J. Iannotti, and T. R. Nansel, "School bullying among adolescents in the united states: physical, verbal, relational, and cyber," Journal of Adolescent Health, vol. 45, no. 4, pp. 368-375, 2009. 

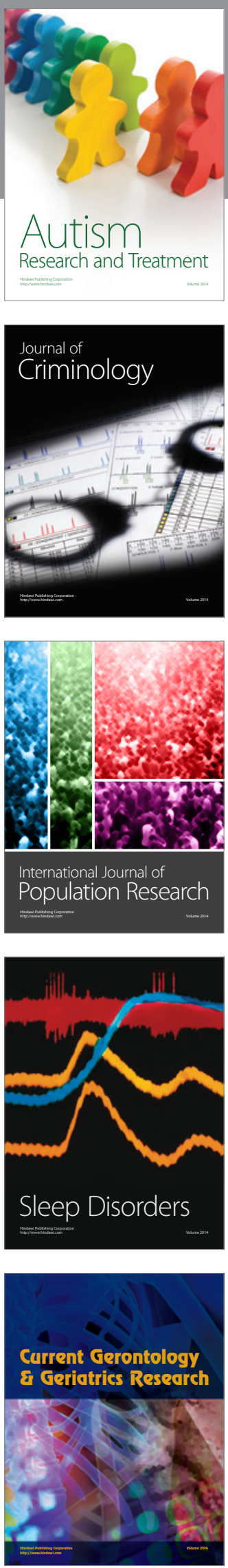
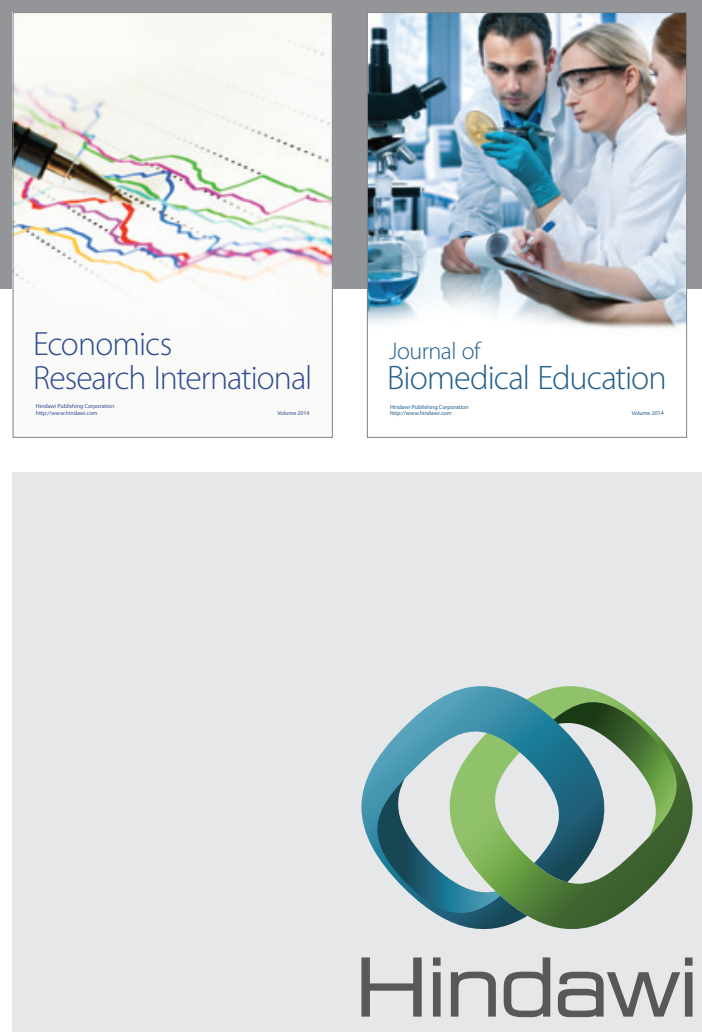

Submit your manuscripts at

http://www.hindawi.com
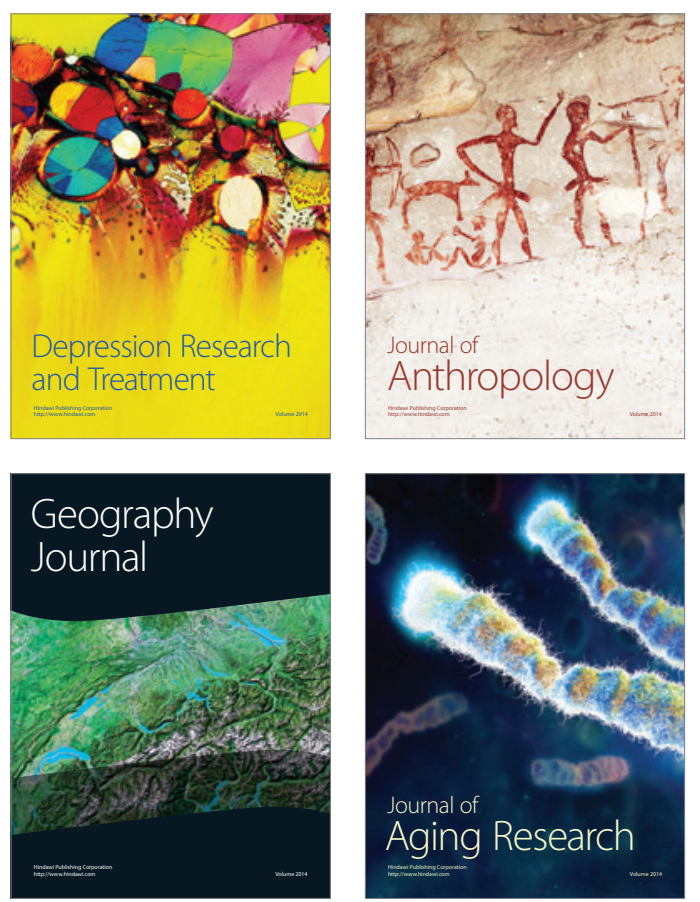
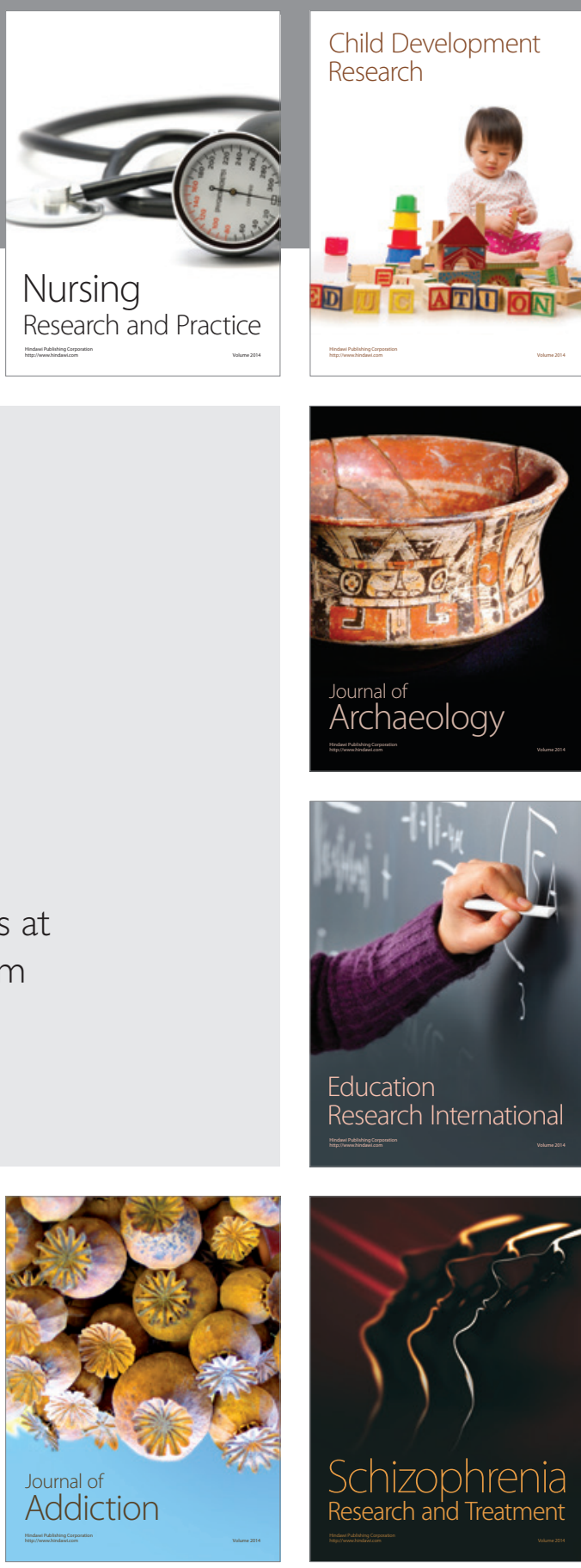

(D)
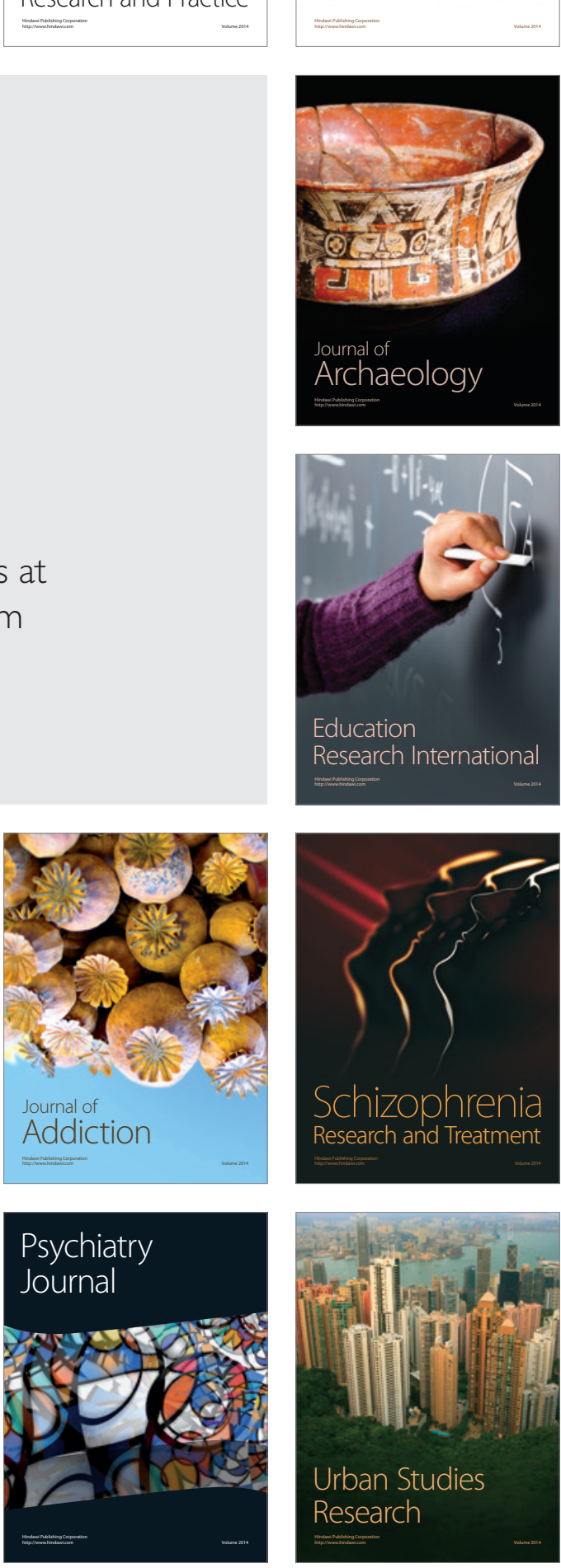